\title{
Síndrome pulmonar por hantavirus: Experiencia clínica en diagnóstico y tratamiento. Hospital Coyhaique-Chile
}

\author{
MAURICIO S. TAPIA G ${ }^{1}$, CARLOS MANSILLA A ${ }^{2}$ y T.M. JOSE L. VERA M * 3 .
}

\begin{abstract}
HANTAVIRUS PULMONARY SYNDROME, CLINICAL EXPERIENCE IN DIAGNOSIS AND TREATMENT. HOSPITAL COYHAIQUE - CHILE
\end{abstract}

From December 1996 to December 1999, 24 patients with Hantavirus Pulmonary Syndrome (HPS) were admitted in the Intensive Case Unit (ICU), with a range of 2 to 60 years old (media 31.8) and $79.2 \%$ were men. The syndrome was manifested with fever, myalgias, stomach aches, nausea, lumbar pain and headache. The diagnosis was based on three criteria: clinical aspects: fever, myalgias, diarrhea vomits, in a person residing in an endemic area; chest $X$-ray: interstitial bilateral infiltrates; blood count: left shift of white series, thrombocytopenia $(<$ $150.000 / \mathrm{mm}^{3}$ ) and an increase of immunoblasts (> $10 \%$ of the lymphocytes). The clinical severity of the HPS could be classified in three groups refered to as mild HPS: that didn't develop shock and required oxygen (n: 7); moderate HPS: that developed moderate shock and required hemodynamic support, mecanical ventilation $(M V)$ and survived (n: 8); severe HPS: that presented with severe shock, required hemodynamic support, $M V$ and finally died (n: 9). Globally the mortality rate was $37.5 \%$ (9/24).

Key words: Hantavirus, Hantavirus Cardiopulmonary Syndrome, Respiratory failure, Acute Respiratory Distress Syndrome.

\section{INTRODUCCION}

El síndrome pulmonar por hantavirus (SPH) fue reconocido por primera vez en 1993 como un brote de síndrome de distress respiratorio agudo (SDRA) de alta letalidad (76\%), en el sur-oeste de E.U.A. ${ }^{1}$ El agente etiológico fue identificado como un nuevo virus ARN del genero Hantavirus (familia Bunyaviridae) - bau- tizado como Virus Sin Nombre (VSN) - que infecta en forma crónica y silenciosa a roedores. $^{2-3}$ Aunque el componente respiratorio del severo cuadro cardio-pulmonar de este síndrome cumple con los criterios de SDRA, ahora sabemos que tiene un cuadro clínico, una patogenia y un tratamiento diferente y particular. En Sudamérica, los tres primeros casos fueron notificados en Brasil en 1993 y luego se

\footnotetext{
Hospital Coyhaique:

${ }^{1}$ Unidad de Cuidados Intensivos

${ }^{2}$ Servicio de Anatomía Patológica

${ }^{3}$ Laboratorio Clínico.
} 
han confirmado casos en Argentina, Paraguay, Uruguay y Bolivia. ${ }^{4-9}$ Se han identificado varios tipos de hantavirus, cada uno de ellos con un reservorio (roedor) específico.

Desde el primer caso presentado en Chile en 1993, hasta julio de 2000, se han notificado 123 casos de SPH con una letalidad de 49,6\% (Depto. Epidemiología. MINSAL. Chile). Los casos chilenos se han distribuido principalmente en regiones del sur del territorio; los primeros dos casos fueron residentes de la X Región del país, en áreas cercanas a la localidad de El Bolsón, Argentina (lugar del brote de ese país en 199395). En estudios de autopsia del segundo de estos casos, un hombre de 22 años, se identificó la presencia de virus Andes ${ }^{5}$ confirmándose la presencia de esta variedad en Chile. En la XI Región de Aysén, se presentó el primer caso regional en la Navidad de $1996^{10}$ y al 31 de diciembre de 1999 se habían presentado 26 casos (2 casos fallecieron antes de ingresar al hospital). En los meses de agosto y septiembre de 1997 hubo un brote de la enfermedad que afectó a tres familias de áreas distantes, relacionado a un aumento en la densidad de roedores potencialmente portadores del virus. En este brote quedó planteada también la transmisión persona-persona de la infección ${ }^{11}$

Describimos a continuación las características clínicas de la enfermedad en 24 pacientes que fueran hospitalizados en la unidad de cuidados intensivos (UCI) del Hospital Coyhaique, XI Región.

\section{PACIENTES Y METODO}

Se hizo un análisis retrospectivo de la historia clínica, examen físico, exámenes de laboratorio, parámetros respiratorios y hemodinámicos en 24 pacientes con SPH de etiología confirmada. El SPH fue definido como: enfermedad con fiebre ( $\left.>38,5^{\circ} \mathrm{C}\right)$, caracterizada por un SDRA no explicable o infiltrados bilaterales en la radiografía de tórax, con compromiso respiratorio que requirió de oxigenoterapia, desarrollado dentro de las primeras 72 horas de hospitalización en una persona previamente sana, o bien, una enfermedad respiratoria aguda conducente a la muerte y en quien la autopsia demostró edema pulmonar no cardiogénico sin causa específica de muerte.

La confirmación etiológica fue realizada por técnicas serológicas (ELISA) que detectan la presencia de inmunoglobulinas específicas contra hantavirus (IgM-IgG).

\section{RESULTADOS}

La edad de los pacientes fluctuó entre 2 y 60 años (media 31,8 años), entre ellos, hubo tres niños bajo 15 años de edad. El 79,2\% era de sexo masculino.

De los 26 casos diagnosticados en la XI Región, 24 ingresaron en la UCI y dos casos fallecieron antes de ingresar al hospital pero pudieron ser confirmados mediante serología específica para hantavirus en muestras de sangre obtenidas postmortem.

\section{Manifestaciones clínicas (Tabla 1)}

Síntomas. La fiebre - criterio de inclusión estuvo siempre presente al ingreso excepto en un paciente pediátrico. Cerca del $60 \%$ de los pacientes presentó un episodio de vómito y/o diarrea los primeros 3 días de la enfermedad. La cefalea holocránea de intensidad moderada fue un síntoma persistente pese al uso de analgésicos. La tos fue un síntoma infrecuente y se observó en etapas tardías de la patología, cuando ya había evidencias de compromiso pulmonar en el examen físico (crepitaciones) y precediendo a la aparición de disnea e insuficiencia respiratoria. Los dolores de grandes masas musculares (cuadriceps, gemelos, pectorales y músculos dorso-lumbares) estaban ya presentes los primeros días de la enfermedad, en más de la mitad de los casos. Alrededor de la mitad de los pacientes presentaba dolor lumbar intenso, en muchos casos referido al flanco derecho (por lo cual fue confundido con cólico biliar).

Signos físicos. Al ingreso fue frecuente observar taquipnea y taquicardia. La mitad de los pacientes que consultaron después del $6^{\circ}$ día de enfermedad tenían crepitaciones en el examen pulmonar. 


\begin{tabular}{|c|c|c|c|c|c|}
\hline Síntomas & $\mathbf{n}$ & $\%$ & Signos & $\mathbf{n}$ & $\%$ \\
\hline $\begin{array}{l}\text { - Fiebre } \\
>38.5^{\circ} \mathrm{C}\end{array}$ & 23 & 96 & $\begin{array}{l}\text { - Frec. Respiratoria } \\
>20 \mathrm{rpm}\end{array}$ & 18 & 75 \\
\hline - Mialgias & 16 & 66 & - Pulso & 16 & 66 \\
\hline - Vómitos/diarrea & 15 & 62 & $>100 \mathrm{ppm}$ & & \\
\hline - Dolor lumbar & 11 & 46 & - Faringitis & 11 & 46 \\
\hline - Cefalea & 10 & 42 & - Crepitaciones & 11 & 46 \\
\hline \multirow[t]{3}{*}{ - Tos } & 8 & 33 & - Petequias & 9 & 38 \\
\hline & & & - Dolor abdominal & 5 & 21 \\
\hline & & & - Congestión ocular & 2 & 8 \\
\hline
\end{tabular}

En un tercio de los pacientes se observaron petequias en tronco y extremidades superiores, apareciendo entre el $6^{\circ}-7^{\circ}$ día; los 3 pacientes pediátricos presentaron, además de las petequias, epistaxis como manifestación hemorrágica externa.

Radiografía de tórax. Al ingreso fue efectuada a 21 pacientes, se observó en todos ellos edema intersticial bilateral leve a moderado (edema pulmonar no cardiogénico, con conservación de la forma y tamaño en la silueta cardíaca). En el estudio radiológico evolutivo se pudo comprobar en algunos pacientes una progresión, desde radiografías de tórax normal o con edema pulmonar leve en las primeras etapas del cuadro ( $3^{\circ}$ a $4^{\circ}$ día), a edema leve que comprometía el $1 / 3$ inferior del pulmón, los días $5^{\circ}$ a $6^{\circ}$ (un enfermo presentó en el curso de su evolución, el día $5^{\circ}$, junto al edema intersticial leve, edema intersticial en parche en un lóbulo superior). Con posterioridad, y aproximadamente en los días $7^{\circ}$ y $8^{\circ}$ de enfermedad, se evidenció un edema pulmonar moderado a severo de todo el parénquima. Edema alveolar masivo fue observado en 4 pacientes en los días $8^{\circ}$ a $11^{\circ}$, en fase avanzada del SPH, dos de los cuales fallecieron.

El derrame pleural fue observado en la radiografía de tórax desde el día $7^{\circ}$ persistiendo hasta los días $11^{\circ}$ a $12^{\circ}$ de evolución.

Ecografía abdominal. Fue realizada a 18 enfermos. En 7 casos (38\%) se describió hepatomegalia y en 3 casos (16\%) esplenomegalia.
En 12 de ellos (66\%) se demostró la presencia de derrame pleural que en 8 de estos no se observaba en la radiografía de tórax concomitante ( $4^{\circ}$ y $8^{\circ}$ días).

Exámenes hematológicos. El hemograma fue fundamental en la sospecha diagnóstica, seguimiento y apreciación de la severidad de la patología (Figuras 1, 2 y 3). Todos los enfermos presentaron a contar del $4^{\circ}$ día de fiebre, algún grado de leucocitosis y desviación a izquierda de la serie blanca. Los que posteriormente fallecieron desarrollaron reacción leucemoide $\left(>20.000 / \mathrm{mm}^{3}\right)$ desde los primeros días de enfermedad y una marcada desviación a izquierda (baciliformes 24-32\%). El hematocrito no presentó grandes variaciones durante la evolución de la enfermedad en los pacientes que sobrevivieron; en cambio, en quienes tuvieron una evolución fatal se observó hemoconcentración (> 45\%) desde el $5^{\circ}$ día, la que se mantuvo hasta su deceso. Todos los pacientes presentaron trombocitopenia progresiva ( $<$ de $150.000 /$ $\mathrm{mm}^{3}$ ) desde los primeros días de fiebre, con variaciones según su gravedad. En algunos se normalizó el valor de las plaquetas (> 150.000/ $\mathrm{mm}^{3}$ ) a contar de $8^{\circ}$ día; en otros se observó una detención del descenso a contar de ese día pero manteniendo valores bajo $150.000 / \mathrm{mm}^{3}$ durante toda la fase de falla cardio-pulmonar y con normalización después del $15^{\circ}$ día. En los pacientes con evolución más grave se apreciaron valores de plaquetas bajo $50.000 / \mathrm{mm}^{3}$ desde los primeros días y el descenso continuó hasta fallecer el $9^{\circ}$ día con cifras de $15.000 / \mathrm{mm}^{3}$. En el 


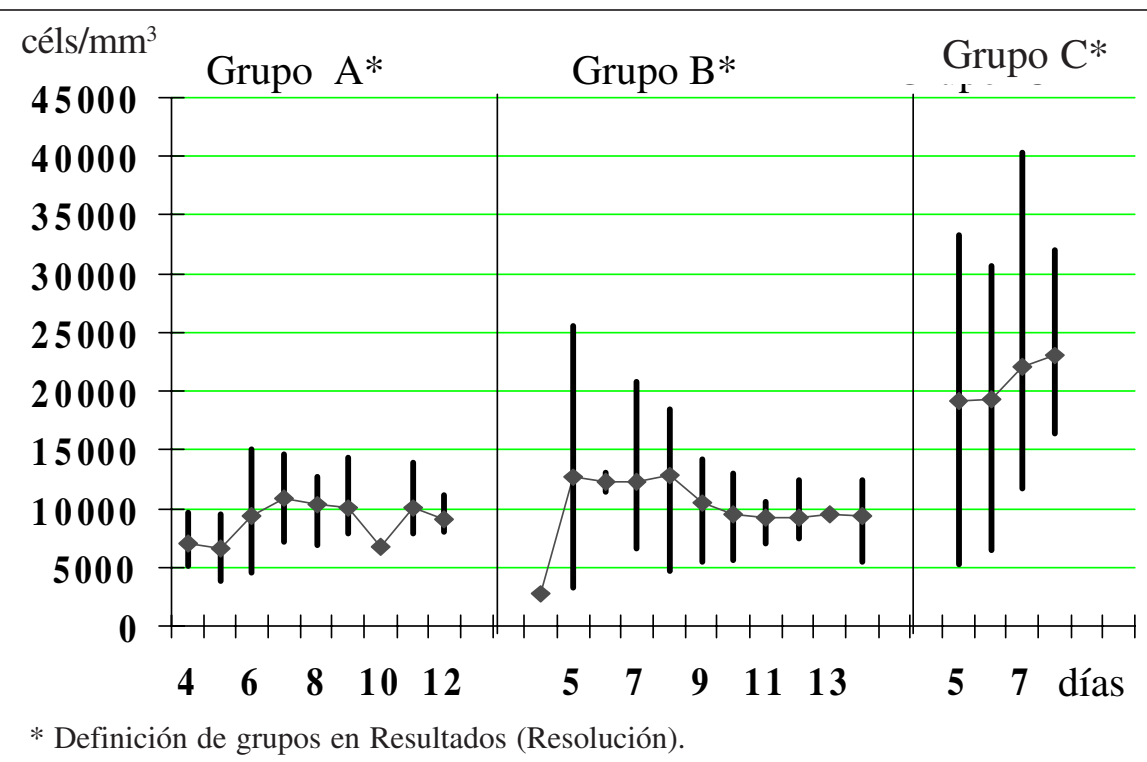

Figura 1. Evolución del recuento leucocitario en casos de síndrome pulmonar por hantavirus, según perfil evolutivo. * Definición de grupos en Resultados (Evolución cardiovascular).

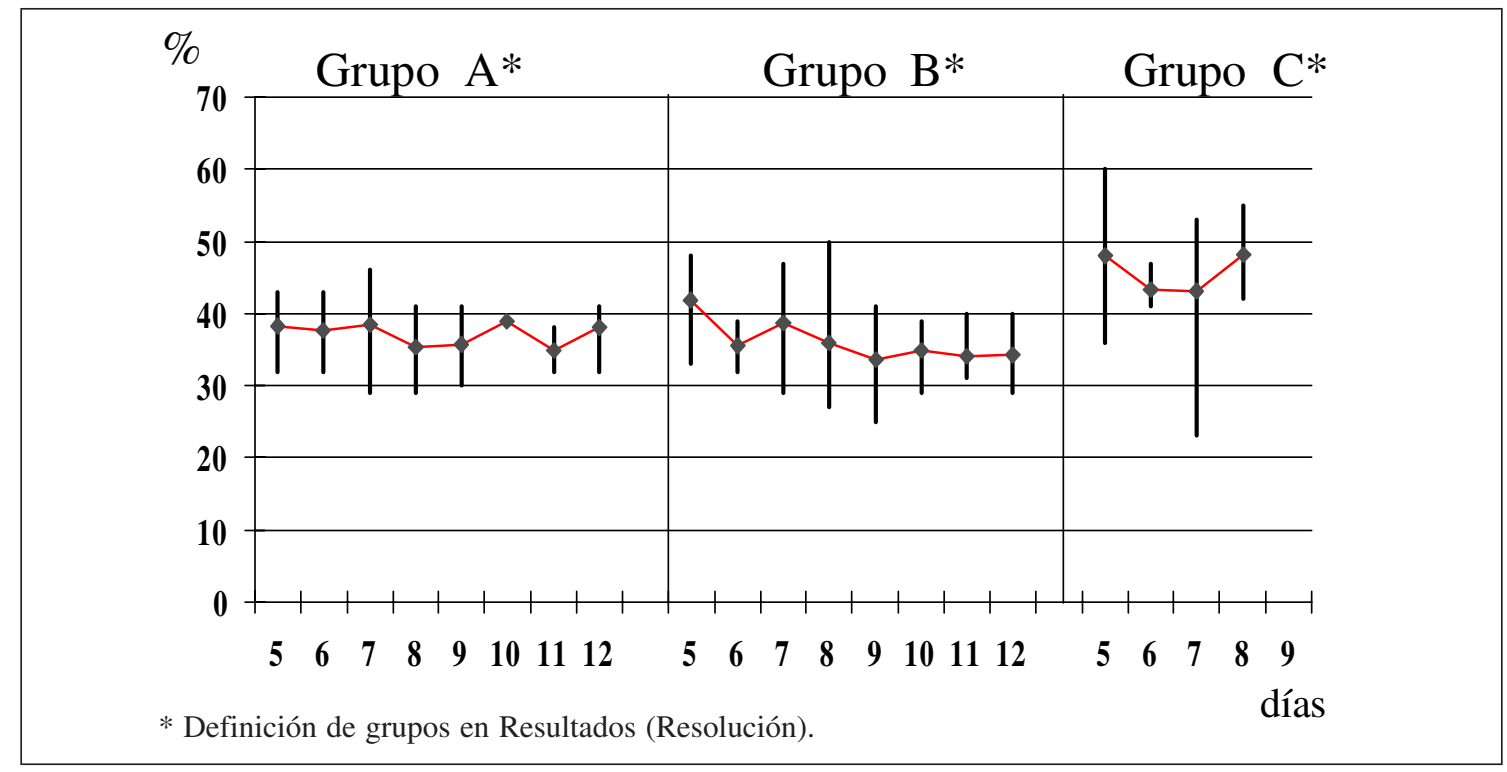

Figura 2. Variación del hematocrito en casos de síndrome pulmonar por hantavirus, según perfil evolutivo. * Definición de grupos en Resultados (Evolución cardiovascular).

examen del frotis sanguíneo de todos los pacientes con SPH fue posible observar inmunoblastos, reconocibles por sus características citológicas (relación núcleo - citoplasma elevado, nucléolos prominentes, citoplasma hiperbasófilo moderado y gránulos citoplasmáticos gruesos), la mayoría de ellos (75\%) con gránulos azurófilos; representaban un porcentaje mayor al $10 \%$ de los linfocitos y permanecieron en circulación durante toda la enferme- 


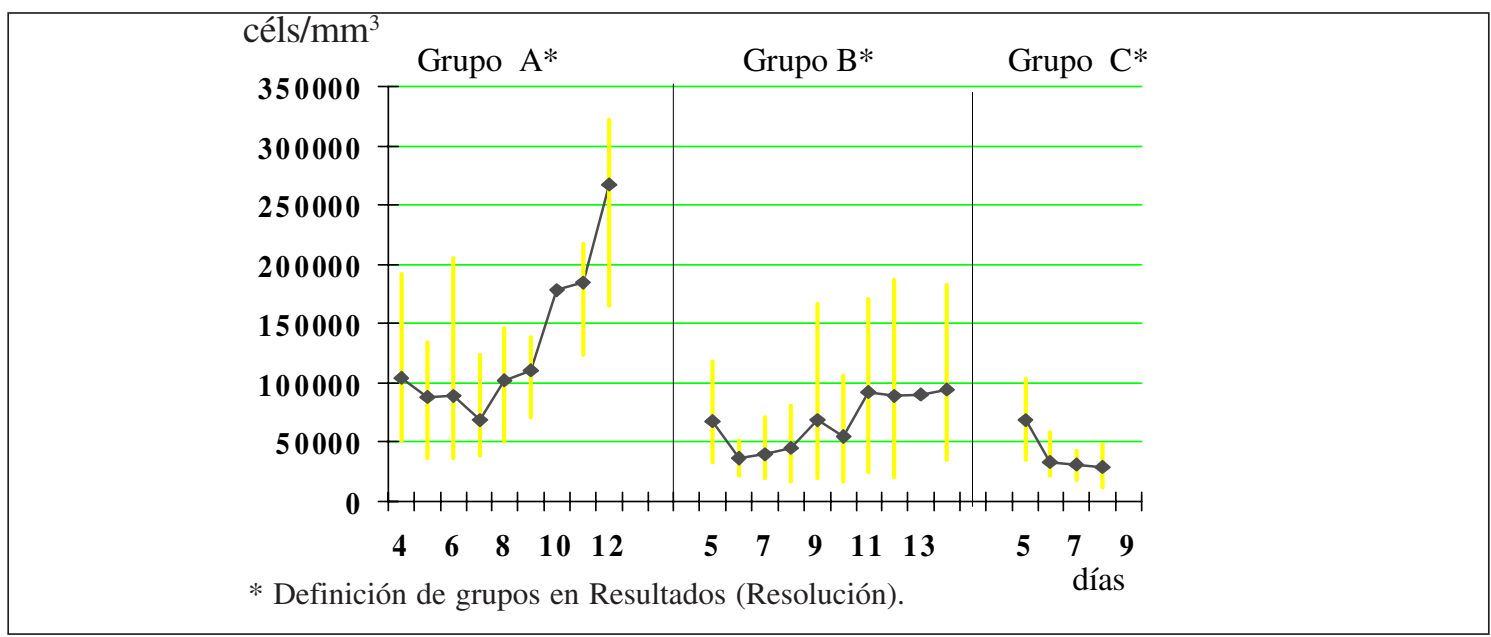

Figura 3. Evolución del recuento plaquetario en síndrome pulmonar por hantavirus, según perfil evolutivo. * Definición de grupos en Resultados (Evolución cardiovascular).

dad. La media de los inmunoblastos en el hemograma de los fallecidos fue de $48 \%$ y de $20 \%$ en los que sobrevivieron, observación similar a la del grupo de K. Nolte en Nueva México. ${ }^{18}$ En los pacientes que fallecieron se encontraban en gran cantidad $(>45 \%)$ desde los primeros días de evolución.

Los exámenes de coagulación como protrombinemia (TP) y tiempo parcial de tromboplastina activada (TTPA) mostraron alteración no significativa en estos enfermos; aunque los valores más elevados $(\mathrm{TP}=13-23$ seg y TTPA $=32-43 \mathrm{seg}$ ) se encontraron en el grupo de los fallecidos, no existió diferencia significativa con los sobrevivientes.

En contraste con otras enfermedades infecciosas la VHS fue normal o en valores ligeramente anormales en todos los pacientes (rango 1-25 mm/hora).

Pruebas bioquímicas. En los enfermos a quienes se les realizó determinación en plasma de enzimas inflamatorias como deshidrogenasa láctica (DHL) fue posible observar su elevación desde el $4^{\circ}$ al $11^{\circ}$ día, media de $698 \mathrm{UI} / 1$ (rango normal de 225-405 UI/l) y pese a ser más elevadas en los pacientes graves que evolucionaron con shock y distress respiratorio, no hubo diferencias significativas entre los fallecidos y los sobrevivientes.

En los pacientes con determinación de creatinfosfokinasa (CPK) plasmática se obser- vó un aumento de valores sobre $600 \mathrm{UI} / \mathrm{l}$ (rango normal 36-236 UI/l) a contar del $7^{\circ}$ día, y al igual que la DHL, se mantuvo elevada hasta el día $10^{\circ}-11^{\circ}$.

Se observó aumento de creatininemia a valores promedios de $1,5 \mathrm{mg} / \mathrm{dl}$ en 7 de nuestros enfermos, en concomitancia con valores elevados de DHL y CPK plasmáticas. No hubo correlación entre valores de creatininemia y la severidad del cuadro clínico. No se observó insuficiencia renal en estos enfermos, a excepción de falla renal aguda una a dos horas antes de fallecer, en los pacientes que evolucionaron hacia el shock refractario. En 16 casos se detectó la presencia de hematuria microscópica y proteinuria leve (30-100 mg/dl), ello podría deberse a compromiso vascular renal ya que el examen histológico postmortem de los riñones efectuados en 10 de 11 pacientes, no demostró daño glomerular.

\section{Evolución respiratoria}

Los 24 pacientes con SPH requirieron oxigenoterapia una vez ingresados a UCI. Cinco casos (1 niño y 4 adultos) desarrollaron insuficiencia respiratoria aguda con $\mathrm{PAFI}\left(\mathrm{PaO}_{2} /\right.$ $\mathrm{FiO}_{2}$ ) entre 200 y 300 y requirieron oxígeno con máscara con una $\mathrm{FiO}_{2}$ sobre $40 \%$. Un niño de 2 años desarrolló al $5^{\circ}$ día de evolución shock, distress respiratorio y una PAFI de 166, pero 
no fue conectado a ventilación mecánica (VM) y sobrevivió. Un adulto de 31 años que no evolucionó hacia el shock ni distress, tenía al $7^{\text {a }}$ día PAFI de 114 y tampoco fue conectado a VM. Dieciséis pacientes desarrollaron una insuficiencia respiratoria severa (entre los días $5^{\circ}-8^{\circ}$ ) progresando a SDRA en menos de 6 - 12 horas (PAFI entre 40-238, en 8 casos < 100) y fueron conectados a VM con $100 \%$ de oxígeno. Dos casos que fallecieron antes de ingresar al hospital también presentaron un cuadro respiratorio agudo no cuantificado.

Un paciente desarrolló un neumotórax espontáneo horas antes de fallecer y dos que sobrevivieron, desarrollaron neumotórax iatrogénico por instalación de un catéter venoso central.

La Tabla 2 muestra una instantánea en los parámetros de gases sanguíneos tomados antes y después de la conexión de los pacientes a VM. Aquellos que fallecieron mostraron, antes de la conexión, valores promedios de saturación de oxígeno y de PAFI más bajos que los demás y todos desarrollaron acidosis metabólica compensada.

Los ocho pacientes que fallecieron en VM experimentaron todas las alteraciones del SDRA, tuvieron un empeoramiento progresivo de la hipoxemia, acidosis no compensada y retención de anhídrido carbónico. Los pacientes en VM que sobrevivieron, mostraron mejoría de los parámetros de oxigenación sanguínea y acidosis metabólica compensatoria. Estos recuperaron rápidamente sus parámetros gasométricos (2448 horas después de haber iniciado la falla cardio-pulmonar).

La resolución de la insuficiencia respiratoria coincidió con una fase de poliuria de 4.000 a $9.000 \mathrm{ml} /$ día, entre los días $7^{\circ}$ y $11^{\circ}$.

\section{Evolución cardiovascular}

Un grupo de enfermos (A) no presentó hipotensión en toda su evolución. Otro grupo (B) cayó en shock $(<100 / 60 \mathrm{mmHg})$ a partir del $4-5^{\circ}$ día, respondiendo rápidamente al uso de fármacos cardiotónicos (dopamina y/o dobutamina) y logrando sobrevivir y, un tercer grupo (C) desarrolló shock y pese a tener una respuesta inicial al uso de cardiotónicos se mantuvo en shock y falleció antes del $9^{\circ}$ día de evolución del cuadro febril.

$\mathrm{Al}$ momento de ingreso al hospital, en quienes se midió la presión venosa central (PVC) ( $4^{\circ}-7^{\circ}$ día), se encontraron valores de 0 a $6 \mathrm{~cm}$ de agua, observándose valores menores a $3 \mathrm{~cm}$ de agua en los pacientes más graves y que fallecieron.

Una mujer del grupo B inició bradicardia (30-35 por min) en el día $9^{\circ}$ de evolución, requiriendo marcapaso transitorio. Al retirarlo el día $14^{\circ}$, se mantuvo con extrasístoles supraven-triculares y ventriculares.

\begin{tabular}{|c|c|c|c|c|}
\hline & \multicolumn{2}{|c|}{ Previo a VM } & \multicolumn{2}{|c|}{$\mathbf{1}^{\mathrm{a}}$ Dìa en VM } \\
\hline & $\begin{array}{c}\text { Grupo B* } \\
(\mathbf{n}=7)\end{array}$ & $\begin{array}{c}\text { Grupo C* } \\
\quad(\mathbf{n}=\mathbf{8})\end{array}$ & $\begin{array}{c}\text { Grupo } B^{*} \\
\quad(\mathbf{n}=7)\end{array}$ & $\begin{array}{c}\text { Grupo C* } \\
\quad(\mathbf{n}=\mathbf{8})\end{array}$ \\
\hline Día de evolución & 6,33 & 6,83 & & \\
\hline $\mathrm{pH}$ & 7,44 & 7,41 & 7,34 & 7,18 \\
\hline $\mathrm{PaO}$ & 71,67 & 53,83 & 101,43 & 67,13 \\
\hline $\mathrm{FIO}_{2}$ & 50,17 & 46,83 & 90,71 & 97,5 \\
\hline PAFI & 180,5 & 138,17 & 131,86 & 71,25 \\
\hline PEEP & & & 4,28 & 5,5 \\
\hline $\mathrm{PaCO}_{2}$ & 25,67 & 22,83 & 32,57 & 42,5 \\
\hline $\mathrm{BE}^{2}$ & $-4,62$ & $-9,03$ & $-6,91$ & $-11,59$ \\
\hline
\end{tabular}


Los pacientes que fallecieron presentaron taquicardia hasta momentos antes del deceso, 2 con taquicardia ventricular y asistolía y 7 cayeron en hipotensión más acentuada y bradicardia extrema que llegó a asistolía, sin responder a maniobras de resucitación.

Los pacientes que experimentaron el deterioro cardio-pulmonar y sobrevivieron, se recuperaron rápidamente y comenzaron una fase poliúrica (4 a 10 litros por día) que duró varios días, exigiendo de una vigilancia estricta del balance hidro-electrolítico. En contraposición, los pacientes que fallecieron 24 a 48 horas después de su ingreso (días $7^{\circ}-9^{\circ}$ ), tuvieron un balance hídrico positivo en 1 a 2 litros por día. Aquellos que sobrevivieron, ingresados entre los días $4^{\circ}-6^{\circ}$ de evolución febril, fueron tratados para obtener un balance hídrico diario de cero o negativo (500 a $2.000 \mathrm{ml}$ en las primeras 24 horas). La resolución del distress respiratorio y del edema pulmonar coincidió en estos enfermos con la fase de poliuria inicial de 3 a 9 litros diarios, que duró desde el $10^{\circ}$ al $15^{\circ}$ días.

\section{Resolución}

Fallecieron 9 de los 24 enfermos, con una letalidad de 37,5\%. Los sobrevivientes habían sido hospitalizados entre los días $2^{\circ}$ y $5^{\circ}$ del inicio de la enfermedad (inicio de la fiebre) y los que fallecieron lo hicieron entre los días $6^{\circ}$ y $8^{\circ}$ $(\mathrm{p}=0,001)$.

Los 15 pacientes que sobrevivieron fueron dados de alta del hospital después de 20 a 45 días de haber iniciado su enfermedad. Los adultos experimentaron durante 2 a 3 meses decaimiento, cansancio, fatiga y poca capacidad respiratoria para trabajar; los dos niños se recuperaron completamente.

Al mes de su alta, a 10 enfermos se les realizó espirometría, en los 8 hombres la espirometría fue normal. Una mujer presentó alteración restrictiva leve y la otra, una obstrucción leve. Ocho de los 10 pacientes presentaban aumento del volumen de reserva espiratoria (VRE $=119$ al $189 \%$ del valor teórico).

De acuerdo a las evolución clínica observada, 7 pacientes fueron catalogados en el grupo $\mathrm{A}$, experimentaron una enfermedad leve requi- riendo oxigenoterapia transitoria sin intubación endotraqueal y estabilidad hemodinámica sostenida durante toda su hospitalización. Ocho pacientes fueron clasificados en el grupo B, requirieron soporte hemodinámico y VM pero sobrevivieron a la enfermedad. Estos enfermos tuvieron hipotensión $(<100 / 60 \mathrm{mmHg})$ que se normalizó con el uso de cardiotónicos (dopamina y/o dobutamina) y mantuvieron una frecuencia cardíaca normal (menor de 99 por min). Los otros 9 pacientes (grupo C) fallecieron pese al enérgico soporte hemodinámico y de VM; después de una normalización transitoria con el uso de cardiotónicos, estos pacientes desarrollaron hipotensión mantenida y taquicardia.

La frecuencia respiratoria fue levemente elevada ( 25 por min) en el examen de ingreso de los pacientes del grupo A y fue elevada y mantenida (32 por min) en los otros dos grupos.

\section{Tratamiento}

Todos los pacientes fueron monitorizados con medidas invasoras (vía venosa central, catéter vesical para efectuar balance hídrico horario) y no invasoras (medición de saturación de oxígeno, presión arterial no invasora y gases arteriales).

El manejo adecuado del aporte de volúmenes fue el principal elemento terapéutico. Se les aportó soluciones coloidales y plasma para obtener un balance hídrico negativo o igual a cero, suficiente para optimizar la volemia (PVC no mayor de $6 \mathrm{~cm}$ agua) y mantener un buen flujo renal.

Una vez ingresados a la UCI, en todos los pacientes adultos se inició el uso de fármacos cardiotónicos (dopamina: 3-10 gamas $/ \mathrm{kg} / \mathrm{min}$ o dobutamina: 1,5-0 gamas $/ \mathrm{kg} / \mathrm{min}$ ), como medida preventiva del shock.

Los adultos fueron tratados empíricamente con antibióticos de amplio espectro asociados (penicilina sódica + cloranfenicol o clindamicina + ceftriaxona), los que se mantuvieron aún una vez confirmado el diagnóstico serológico de infección por hantavirus.

Además de la oxigenoterapia ya comentada, desde septiembre de 1997 se inició la administración de metilprednisolona en los primeros días del SPH según el siguiente esquema: 1.000 
mg e/v diario en infusión continua durante 72 horas, luego $16 \mathrm{mg} /$ día oral durante 3 días, 8 $\mathrm{mg}$ /día durante otros 3 días y finalmente $3 \mathrm{mg}$ / día los últimos 3 días. Desde que se inició el uso de metilprednisolona la letalidad ha disminuido a $18,2 \%(2 / 11)$ comparada con la letalidad histórica en la Región, de 53,8 \% (7/13).

\section{DISCUSION}

Desde la presentación del primer caso de SPH en la Región de Aysén, nos hemos enfrentado a una nueva enfermedad que afecta a pacientes de todas las edades. A diferencia del primer caso descrito en diciembre de 1996, que falleció en menos de 24 horas desde su ingreso al hospital, no todos los pacientes han presentado esa evolución. Con el tiempo se ha observado diversas expresiones clínicas de la infección por hantavirus: asintomática, casos leves que no requieren ventilación mecánica y otros más graves que sí requieren ventilación mecánica por insuficiencia respiratoria, evolucionando una parte de ellos hacia el shock, insuficiencia respiratoria con hipoxemia severa y, pese a un tratamiento agresivo en UCI, han fallecido. Hallazgos similares fueron descritos en el brote de esta enfermedad en 1993-1994 por G. Hallin et al. $^{12}$

El cuadro clínico general de los pacientes en esta serie ha sido similar al observado en otros episodios respiratorios de causa viral: fiebre, mialgias de grandes masas musculares, manifestaciones abdominales inespecíficas, cefalea y compromiso del estado general. Sin embargo, el catarro nasal observado en la influenza (coriza y congestión nasal) estuvo ausente. ${ }^{13}$ La tos ha sido un síntoma tardío y precedente de la insuficiencia respiratoria (injuria pulmonar que no tiene disnea previa) por unas horas, hecho semiológico que podría constituirse en un indicador premonitorio del distress.

Los casos en esta serie se distinguieron de los descritos en E.U.A. para el virus Sin Nombre por la presencia de petequias, en un tercio de los casos, y a la existencia de manifestaciones hemorrágicas, en un niño fallecido. En la descripción inicial de E.U.A. ${ }^{1}$ no se describieron hemorragias; sin embargo, ellas son frecuentes en la fiebre hemorrágica con síndrome renal (FHSR) descrito en Asia y Europa. ${ }^{14}$ Difieren también del SPH del sur-este de Argentina, producido por el virus Andes, brote en el cual se destacó la descripción clínica de rubicundez (congestión facial y del cuello) pero no se apreciaron manifestaciones hemorrágicas.

El 46\% de los pacientes adultos manifestó dolor abdominal y/o lumbar importante como síntoma de los primeros días, a diferencia del $24 \%$ observado por J. S. Duchin et al. ${ }^{1}$ En los pacientes con FHSR el dolor lumbar ha sido frecuente (35-78\%) y es consecuencia de extravasación de plasma en el tejido retroperitoneal y espacio peritoneal. ${ }^{14} \mathrm{La}$ TAC realizada a los pacientes norteamericanos que presentaron un SPH con dolor abdominal, no demostró la presencia de líquido en el espacio retroperitoneal; en las ecografías de abdomen y autopsias realizadas a nuestros enfermos tampoco se evidenció presencia de líquido en estos espacios, por lo cual no queda clara la causa del dolor abdominal y lumbar de estos enfermos.

Las mialgias de grandes masas musculares es otro síntoma común en los enfermos; $100 \%$ en el grupo de Duchin y 66\% en el nuestro. El grupo de Nuevo México ${ }^{16}$ describió una variedad de hantavirus (Bayou) que produce síndrome pulmonar asociado además a elevados niveles plasmáticos de DHL y CPK. Por determinación de electroforesis de isoenzimas concluyeron que esto se debería a una rabdomiolisis de musculatura estriada. En los pacientes de Duchin et al, se observó una media de DHL de 568 UI/l (rango normal 180-237 UI/l) y en nuestra casuística una media de 698 UI/l (rango normal 225-405 UI/1). En cinco de nuestros enfermos se realizó determinación de CPK, con valores entre 166-1.071 UI/1 y una media de $591 \mathrm{UI} / 1$ (rango normal 36-236 UI/l) comparado con el grupo de pacientes presentados por Duchin et al, en los que se observó CPK en rango de 19 $1.029 \mathrm{UI} / 1$, con media de $46 \mathrm{UI} / 1$ (rango normal 180-269 UI/1). El aumento muy importante de estas enzimas podría explicar, al igual que en los pacientes afectados por el hantavirus Bayou, que los dolores musculares y lumbares en nuestros pacientes, pudieran deberse a una lisis de la musculatura estriada.

De acuerdo a S. Jenison et al, la triada 
trombocitopenia, desviación a izquierda de la serie blanca y la existencia de inmunoblastos ( $>$ al $10 \%$ de los linfocitos), se encuentra en todos los pacientes con SPH y en ningún otro enfermo con SDRA por otra causa infecciosa que simule al SPH. ${ }^{17}$ Los inmunoblastos se buscaron en forma dirigida en 20 casos ingresados con la sospecha diagnóstica de $\mathrm{SPH}$, en 18 de ellos la presencia de estas células dio la orientación diagnóstica 48 horas antes de obtener la confirmación serológica (los dos restantes resultaron ser septicemia por Streptococcus del grupo C).

En el momento del ingreso de los pacientes al hospital ya manifestaron pequeñas diferencias que predijeron el curso y la severidad de la enfermedad. Aquellos que presentan frecuencia cardíaca, frecuencia respiratoria y presión arterial en rangos normales experimentaron compromiso respiratorio y un cuadro clínico leves. Los que presentaron desde el ingreso taquicardia, taquipnea e hipotensión, evolucionaron con enfermedad moderada o severa. La inestabilidad hemodinámica marcó la diferencia entre los pacientes que sobrevivieron o fallecieron. La falta de respuesta presora e inotrópica al uso de dopamina en adición a hipovolemia $(\mathrm{PVC}<3$ $\mathrm{cm}$ agua) fue un factor muy importante en los pacientes que fallecieron; este hecho ha sido descrito por todos los grupos. Aquellos que han usado catéter de Swan-Ganz y medido presión de enclavamiento de arteria pulmonar, índice cardíaco y resistencia vascular sistémica ${ }^{1-12}$ han encontrado parámetros exclusivos de esta enfermedad: presión de enclavamiento normal o baja, índice cardíaco muy bajo y resistencia vascular aumentada. Este patrón hemodinámico es muy distinto a lo observado en enfermos con shock séptico de otras etiologías, pacientes que presentan índice cardíaco elevado y resistencia vascular sistémica baja. ${ }^{15}$

La función renal en los pacientes con SPH por virus Sin Nombre no está alterada. En nuestros pacientes no se describió oliguria o anuria en el curso de la enfermedad, salvo en las etapas terminales del shock. Proteinuria y azoemia se han explicado como una consecuencia directa de la miositis de la infección por hantavirus lo cual podría explicar los hallazgos en nuestros pacientes. ${ }^{16}$
El análisis de trabajos que muestran claros beneficios del uso de corticosteroides en pacientes con sepsis severa y SDRA, en meningitis bacteriana aguda, ${ }^{21}$ fiebre tifoidea grave,,$^{22}$ en lesión medular aguda ${ }^{23}$ y en neumonía por Pneumocystis carinii, ${ }^{24-25}$ estimuló la iniciativa de emplear corticoterapia enérgica y precoz. En el supuesto de que el uso de corticosteroides en etapas tempranas de la enfermedad, antes del inicio de la cascada inflamatoria, era capaz de reducir la severidad de la enfermedad e incluso su letalidad, se introdujo el uso de metilprednisolona a altas dosis y en infusión continua, en el pródromo del SPH. Se observó que el uso de metilprednisolona, antes de la instalación de la fase cardio-pulmonar, se asoció a una evolución clínica caracterizada por menor severidad del shock y una menor letalidad. Dos de 11 pacientes tratados con metilprednisolona $(18,2 \%)$ fallecieron, en oposición a lo observado en quienes no recibieron metilprednisolona: 7 de 13 (53,8\%). Quienes recibieron metilprednisolona a partir de los días $4^{\circ}$ a $5^{\circ}$ de haber iniciado el cuadro febril no evolucionaron hacia el shock ni SDRA mientras la mitad de quienes la recibieron a partir del día $6^{\circ}$, desarrolló shock moderado y 3 de 4 presentaron SDRA. Esta información no representa resultados obtenidos en un estudio controlado por placebo y ciego. Otros factores como la detección más precoz de la infección, asociada a la experiencia que se adquirió en su diagnóstico, la hospitalización más temprana y la mayor familiaridad con el manejo de estos pacientes, intervinieron probablemente en la disminución de la letalidad. Esta menor letalidad lograda con el tiempo, ha sido observada ya en los centros norteamericanos que atienden pacientes desde 1993.

Los principales predictores de un curso fatal en esta serie de pacientes fueron la hospitalización tardía (después del $7^{\circ}$ día), presencia de hipotensión al momento de ingreso al hospital y falta de respuesta a fármacos cardiotónicos. También se asociaron a mala evolución la presencia en el frotis sanguíneo de leucocitosis mayor de $20.000 / \mathrm{mm}^{3}$, trombocitopenia menor de $50.000 / \mathrm{mm}^{3}$, hematocrito mayor de $45 \%$, inmunoblastos mayor de $45 \%$ en relación a los linfocitos, parámetros de gases arteriales con 
PAFI menor de 150 previo a VM y menor de 70 en VM, pH menor de 7,20 en VM. (datos no presentados)

En nuestra experiencia cuatro niños han adquirido infección por hantavirus, uno de ellos asintomático, dos desarrollaron SPH leve sin inestabilidad hemodinámica y falla respiratoria leve y uno evolucionó con SPH severo falleciendo. Los sintomáticos presentaron petequias en el curso de la enfermedad. En los primeros 100 casos de SPH descritos en E.U.A., ocho fueron niños entre 11 y 16 años de edad, ${ }^{26}$ incluyendo una completa descripción de un adolescente de 14 años que desarrolló un SPH y falleció. ${ }^{27}$ También se ha reportado el caso de un niño de 4 años que presentó una forma leve sin manifestación respiratoria. ${ }^{28}$ La presencia de niños en nuestra casuística confirmó que la infección por hantavirus existe a toda edad. No es infrecuente (17\%) y puede presentarse en todas sus formas, lo cual nos obliga a considerar al SPH como diagnóstico diferencial de distress respiratorio o neumonía atípica bilateral en niños procedentes de zonas donde la existencia de la enfermedad ha sido confirmada.

La transmisión persona-persona de este virus ha sido estudiada in extenso desde el primer brote reportado de SPH. Un estudio serológico realizado a trabajadores de la salud que estuvieron en contacto con enfermos de SPH durante el mismo brote ocurrido en E.U.A. ${ }^{19}$ no detectó anticuerpos contra hantavirus en ninguno de ellos, sugiriendo de este tipo de transmisión por virus Sin Nombre no se produce en el ambiente hospitalario. En oposición, este tipo de transmisión ha sido bien documentada para el virus Andes en el brote de El Bolsón, Argentina, donde la enfermedad fue transmitida a un médico en un lugar muy distante del lugar de infección ambiental, por un paciente. ${ }^{6}$ En nuestro país se efectuó un estudio de prevalencia de la infección por hantavirus, en el personal del Hospital Coyhaique durante el brote de 1997 y que demostró ausencia de transmisión nosocomial. ${ }^{20}$ Sin embargo, la transmisión persona-persona no pudo ser excluida en dos grupos familiares de los tres que constituyeron ese brote. ${ }^{11}$ Por lo tanto, hasta que la transmisión persona-persona del virus Andes en nuestro país no sea completamente clarificada, es recomendable hospitalizar en régimen de aislamiento respiratorio a todo paciente con sospecha de esta infección y el personal hospitalario debe observar rigurosamente las medidas de protección universal establecidas para ello.

\section{CONCLUSIONES}

- El SPH se presenta en 5 fases: incubación (5 a 45 días), pródromo ( $1^{\circ}$ a $6^{\circ}$ días $)$ donde se presentan los síntomas, alteraciones hematológicas y de imágenes, falla cardiopulmonar $\left(6^{\circ}\right.$ a $9^{\circ}$ días $)$, poliuria $\left(10^{\circ}\right.$ a $15^{\circ}$ día) y convalecencia, (2 a 3 meses).

- La fiebre es el síntoma y signo clave del SPH ya que a contar del inicio de ella, la enfermedad toma un curso mantenido y predecible.

- En sus comienzos el SPH se manifiesta con fiebre, mialgias, molestias digestivas, dolor lumbar y cefalea.

- Cada día se suman nuevos síntomas, alteraciones hematológicas y radiológicas que nos ayudan en la sospecha diagnóstica.

- El diagnóstico operacional se debe plantear a base de tres criterios: cuadro clínico: fiebre, mialgias, diarrea y/o vómitos y residencia o permanencia reciente en zona endémica; $r a-$ diografía de tórax: infiltrado intersticial bilateral; hemograma que muestra desviación a izquierda de la serie blanca, trombocitopenia $\left(<150.000 / \mathrm{mm}^{3}\right)$ y la presencia de inmunoblastos (>10\% de los linfocitos).

- La confirmación etiológica se hace en Chile con serología (ELISA, demostrando IgM y/o IgG contra hantavirus), también se puede efectuar mediante RPC y con métodos de inmunohistoquímica.

- Todo paciente con sospecha de SPH debe ser hospitalizado en una UCI, donde el tratamiento va orientado a prevenir el shock y el SDRA.

- Se debe tener un manejo muy cuidadoso de los volúmenes (usar soluciones coloidales) buscando rápidamente obtener un balance hídrico igual a cero o negativo.

- Todos los pacientes deben recibir apoyo farmacológico para la bomba cardíaca con 
cardiotónicos, incluso antes que desarrollen shock. Esto también ayuda a proteger la función renal.

- La hipoxemia es el resultado final del edema pulmonar en el SPH por lo cual todos deben recibir oxigenoterapia con máscara o $\mathrm{VM}$ convencional precoz (con valores de PAFI entre 300-350, antes de manifestarse la injuria pulmonar).

- Mientras se establece el diagnóstico etiológico se debe iniciar antibióticos de amplio espectro, los que debieran interrumpirse una vez confirmada la presencia de hantavirus.

- La modulación de la respuesta inmunitaria en la fase de pródromo precoz para intentar disminuir la severidad de la enfermedad y con ello su letalidad, es una estrategia teórica que merece ser evaluada en estudios prospectivos, controlados y randomizados.

- En nuestra casuística pudimos observar tres formas evolutivas: SPH leve sin shock y que requiere oxigenoterapia clásica; SPH moderado con shock moderado, que requiere soporte hemodinámico y VM, pero con resolución favorable; SPH severo con shock severo, refractario y que conduce al deceso.

- Factores asociados a mortalidad en nuestra experiencia fueron: hospitalización tardía ( $>7^{\circ}$ día), hipotensión al ingreso y falta de respuesta a cardiotónicos, leucocitosis $>$ de $20.000 / \mathrm{mm}^{3}$, trombocitopenia $<$ de $50.000 /$ $\mathrm{mm}^{3}$, hematocrito $>$ de $45 \%$, inmunoblastos $>$ de $45 \%$, PAFI $<150$ previo a $\mathrm{VM} \mathrm{y}<70$ en $\mathrm{VM}, \mathrm{pH}<$ de 7,20 en VM.

\section{RESUMEN}

Entre diciembre de 1996 y diciembre de 1999, se ingresaron a la Unidad de Cuidados Intensivos del Hospital Coyhaique, 24 pacientes con síndrome pulmonar por hantavirus (SPH), con un rango de edad entre 2 y 60 años, (media 31,8), de los cuales 19 (79,2\%) eran de sexo masculino. El SPH se manifestó con fiebre, mialgias, molestias digestivas, dolor lumbar y cefalea. El diagnóstico se basó en los siguientes tres criterios: cuadro clínico: fiebre, mialgias, diarrea y/o vómitos, en residente de zona endémica; radiografía de tórax: infil- trado intersticial bilateral; hemograma: desviación a izquierda de serie blanca, trombocitopenia $(<150.000 / \mathrm{ml})$ e inmunoblastos $(>10 \%$ de los linfocitos). La severidad clínica del SPH se pudo estratificar en tres grupos: SPH leve: no evolucionaron con shock y requirieron sólo oxigenoterapia (n: 7); SPH moderado: desarrollaron shock moderado, requirieron soporte hemodinámico, ventilación mecánica (VM) y sobrevivieron (n: 8); SPH severo: desarrollaron shock severo, requirieron de soporte hemodinámico, VM y fallecieron (n: 9). La letalidad general fue de $37,5 \%(9 / 24)$.

\section{BIBLIOGRAFIA}

1.- DUCHIN J S, KOSTER F T, PETERS C J et al. Hantavirus pulmonary syndrome: a clinical description of 17 patients with a newly recognized disease. N Engl J Med 1994; 330: 949-55.

2.- SCHMALJOHN C, HJELLE B. Hantaviruses: a global diseases problem. Emerg Infect Dis 1997; 3(2): 95-104.

3.- MERTZ G, HJELLER B, BRYAN R. Hantavirus infection. En: Fauci A, Schrier R, editores. Advances in Internal Medicine. Chicago: Mosby Year Book Inc., 1996: 369-421.

4.- IVERSSON L B, DA ROSA A P et al. Human infection by hantavirus in southern and south eastern Brazil. Rev Asoc Med Bras 1994; 40: 85-92.

5.- LOPEZ N, PADULA P, ROSSI $\mathrm{C}$ et al. Genetic characterization and phylogeny of Andes virus from Argentina and Chile. Virus Res 1997; 50:77-84.

6.- WELLS R M, ESTANI S S, YADON Z E et al. An unusual hantavirus outbreak in southern Argentina: person-to-person transmission? Emerg Infect Dis 1997; 3:171-4.

7.- WILLIAMS R J, BRYAN R T, MILLS J N, PALMA E et al. An outbreak of hantavirus pulmonary syndrome in western Paraguay. Am J Trop Med Hyg 1997; 3: 274-82.

8.- HJELLE B, TORREZ-MARTINEZ N, KOSTER F. Hantavirus pulmonary syndrome-related virus from Bolivia. The Lancet 1996; 347 (8993): 57.

9.- BHARADWAJ M, BOTTERN J, TORREZMARTINEZ N, HJELLE B. Río Mamore virus: genetic characterization of a newly recognized hantavirus of the pygmy rici rat, Oligoryzomys microtis, from Bolivia. Am J Trop Med Hyg 1997; 57 (3): 368-74.

10.- TAPIA M. Síndrome pulmonar por hantavirus: Caso clínico. Rev Chil Enf Respir 1997; 13: 103-10.

11.- TORO J, VEGA J, KHAN A et al. An oubreak of hantavirus pulmonary syndrome, Chile 1997. Emerg Infect Dis 1998; 4: 667-702.

12.- HALLIN G, SIMPSON S, CROWELL R et al. 
Cardiopulmonary manifestations of hantavirus pulmonary syndrome. Crit Care Med 1996; 4 (2): 252-8.

13.- MOOLENAAR R L, DALTON C, LIPMAN H B et al. Clinical features that differentiate hantavirus pulmonary syndrome from three other acute respiratory illnesses. Clin Infect Dis 1995; 21 (3): 643-9.

14.- BRUNO PH, HASSELL H, BROWN J, TANNER $\mathrm{W}$, LAU A. The protean manifestations of hemorrhagic fever with renal syndrome. A retrospective review of 26 cases from Korea. Ann Intern Med 1990; 113 (4): 385-91.

15.- PARKER M, PARRILLO J. Septic shock. Hemodynamics and pathogenesis. JAMA 1983; 250: 3324-7.

16.- HJELLE B, GOADE D, TORREZ-MARTINEZ N, LANG-WILLIAMS M, KIM J, HARRIS R, RAWLINGS J. Hantavirus pulmonary syndrome, renal insufficiency, and myositis associated with infection by Bayou hantavirus. Clin Infect Dis 1996; 23: 495-500.

17.- JENISON S, HJELLER B, SIMPSON S, HALLIN G, FEDDERSEN R, KOSTER F. Hantavirus pulmonary syndrome: clinical, diagnostic and virologic aspects. Seminars Respiratory Infections 1995; 10 (4): 259-69.

18.- NOLTE K, FEDDERSEN R, FOUCAR K, ZAKI S, KOSTER F, MADAR D, MERLIN T, MCFEELEY P, UMLAND E, ZUMWALT R. Hantavirus pulmonary syndrome in the United States: A pathological description of a disease caused by a new agent. Hum Pathol 1995; 26: 110-20.

19.- VITEK C H, BREIMAN R, KSIAZEK T, ROLLIN P, MCLAUGHLIN J, UMLAND E. Evidence against person-to-person transmission of hantavirus to health care workers. Clin Infect Dis 1996; 22: 824-6.

20.- CHAPPARO J, VEGA J, TERRY W, BARRA B, MEYER R, PETERS C J, KHAN A S, KSIAZEK T G. Assessment of person-to-person transmission of hantavirus pulmonary syndrome in a Chilean hospital setting. J Hosp Infect 1998; 40: 281-5.

21.- LEBEL M H, FREIJ B J, SYROGAINNOPOLOUS $\mathrm{G}$ A et al. Dexamethasone therapy for bacterial meningitis: results of two double-blind placebo- controlled trials. N Engl J Med 1988; 319: 964-71.

22.- HOFFMAN S L, PUNJABI N H, KUMALA S et al. Reduction of mortality in chloramphenicol-treated severe typhoid fever by high-dose dexamethasone. N Engl J Med 1984; 310(2): 82-8.

23.- BRACKEN M B, SHEPARD M J, COLLINS W F et al. A randomized, controlled trial of methylprednisolone or naloxone in the treatment of acute spinal cord injury. N Engl J Med 1990; 322:1405-11.

24.- EL-SADR W, SIDHU G, DIAMOND G et al. Highdose corticosteroids as adjuvant therapy in severe Pneumocystis carinii pneumonia. AIDS Res 1986; 2(4): 349-55

25.- MONTANER J S, LAWSON L M, LEVITT N, BELZBERG A, SCHECHTER M T, RUEDY J. Corticosteroids prevent early deterioration in patients with moderately severe Pneumocystis carinii pneumonia in the acquired immunodeficiency syndrome. Ann Intern Med 1990; 113:14-20.

26.- KHAN A S, KHABBAZ R F, ARMSTRONG L R et al. Hantavirus pulmonary syndrome: the 100 first US cases. J Infect Dis 1996; 173:1297-3031.

27.- KHAN A S, KSIAZEK T G, CHEEK J E et al. Fatal hantavirus pulmonary syndrome in an adolescent. Pediatrics 1995; 95: 276-80.

28.- ARMSTRONG L, BRYAN R, SARISKY J, KHAN A $S$ et al. Mild hantavirus disease caused by $\mathrm{Sin}$ Nombre Virus in a four-year-old child. Pediatr Infect Dis J 1995; 14(12): 1108-10.

Agradecimientos. Nuestro reconocimiento al apoyo brindado a este trabajo por el proyecto 5 UI9 AI 45452-02 del Instituto Nacional de Alergias y Enfermedades Infecciosas del National Institutes of Health, Bethesda, Maryland, E.U.A. En particular agradecemos a los científicos G. J. Mertz, B. Hjelle y A. Khan. Por la revisión de este manuscrito a P. Vial C. y J. Cofré G.

Correspondencia a:

Mauricio S. Tapia Gaete,

Fax (67) 232843

e-mail: sewell55@entelchile.net 